\title{
INFLUENCIA DE DIFERENTES FONTES DE CARBONO NO CRESCIMENTO E NA SÍNTESE DE CELULASES PELO FUNGO Myceliophthora thermophila M.7.7
}

\author{
D. A. C. MUNHOZ ${ }^{1 *}$; A. C. G. SANTOS ${ }^{2}$; J.C.THOMÉO ${ }^{1}$ \\ ${ }^{1}$ Universidade Estadual Paulista, Departamento de Engenharia e Tecnologia de \\ Alimentos \\ *E-mail para contato: davidandreca@gmail.com
}

RESUMO - O objetivo do presente trabalho foi compreender o efeito de diferentes fontes de carbono na cinética de crescimento e na secreção de celulases pelo fungo Myceliophthora thermophila M.7.7 em cultivo submerso (Csb). Os ensaios foram conduzidos a $45^{\circ} \mathrm{C}$ sem agitação por 96 horas, com pontos iniciando do tempo zero e seguindo a cada 24 horas. As fontes de carbono foram testadas em concentrações de $0,5 \%$ e $1,5 \%$ dentro da cinética citada. As fontes de carbono testadas foram glicose, celobiose, lactose e xilose. Métodos analíticos foram empregados para a determinação das concentrações de biomassa e a análise enzimática foi baseada na determinação de açúcares redutores totais. A máxima concentração de micélio seco foi obtida em $0,5 \%$ de glicose em 72 horas de crescimento, já o pico de atividade enzimática foi observado durante o cultivo com $0,5 \%$ de xilose e celobiose no tempo de 72 horas de cultivo. O presente trabalho nos permitiu concluir que o tipo e a concentração da fonte de carbono estão estreitamente relacionados com o crescimento e a secreção de celulases

\section{INTRODUÇÃO}

Nas últimas décadas, a busca por novas tecnologias e o interesse em estudos do sistema celulolítico de fungos termófilos aumentou consideravelmente o desenvolvimento de pesquisas visando a ampla utilização das suas enzimas em diversos setores industriais e aplicações biotecnológicas.

De acordo com Krishna (2005), a produção de enzimas microbianas pode seguir duas rotas: a de cultivo submerso (CSb) e a de cultivo sólido (CES). O CSb é consagrado industrialmente e há domínio satisfatório das técnicas experimentais em várias escalas, sendo disponíveis comercialmente vários equipamentos em escalas variadas, de bancada a industriais.

Um dos fatores básicos para uma eficiente produção de enzimas por microrganismos, refere-se à adequada escolha do substrato e a otimização da composição do meio de cultivo, pois, a partir daí, pode-se definir as características da enzima, bem como controlar a formação de compostos indesejáveis. 
O crescimento microbiano e a resultante formação do produto ocorrem em resposta ao meio ambiente de modo interativo. Portanto, em um processo fermentativo é essencial entender a relação entre a regulação do metabolismo e o ambiente em que o fungo está exposto, assim como cada estágio de desenvolvimento do fungo.

O fungo Myceliophthora thermophila possui um conjunto dinâmico de complexos protéicos (Berka et al., 2011) que apresentam variações como consequência às alterações ambientais, por exemplo, em relação à fonte de carbono. O objetivo deste trabalho foi avaliar a metabolização enzimática e crescimento da biomassa do fungo Myceliophthora thermophila M.7.7 frente à variação da concentração de fontes de carbono.

\section{MATERIAIS E MÉTODOS}

Os ensaios foram realizados no Laboratório de Engenharia de Processos e Biorreatores do IBILCE/UNESP.

\subsection{Microrganismo}

A linhagem de Myceliophthora thermophila M.7.7 pertence à coleção do Laboratório de Microbiologia e Bioquímica Aplicada do IBILCE/UNESP e foi isolada por Moretti (2010) em pilhas de bagaço de cana de açúcar na Usina Guarani, Olímpia - SP. A linhagem do fungo foi mantida em tubos de ensaio contendo meio de cultivo Agar-Sabouraud-Dextrose (ASD) inclinado, submerso em óleo mineral, mantendo-se os tubos a $5^{\circ} \mathrm{C}$. Para cada cultivo foi feito um préinóculo em frasco erlenmeyer de $250 \mathrm{~mL}$, contendo $50 \mathrm{~mL}$ de meio nutriente sólido (ASD) inclinado.

\subsection{Meio nutriente e condições de cultivo}

Os cultivos submersos foram realizados em frascos Erlenmeyer de $125 \mathrm{~mL}$, contendo $20 \mathrm{~mL}$ do meio nutriente composto por: Peptona $(1 \mathrm{~g} / \mathrm{L}) ;\left(\mathrm{NH}_{4}\right)_{2} \mathrm{SO}_{4}$ $(0,5 \mathrm{~g} / \mathrm{L}), \mathrm{K}_{2} \mathrm{HPO}_{4}(2 \mathrm{~g} / \mathrm{L}), \mathrm{MgSO}_{4} \cdot 7 \mathrm{H}_{2} \mathrm{O}(0,3 \mathrm{~g} / \mathrm{L}), \mathrm{CaCl}_{2}(0,4 \mathrm{~g} / \mathrm{L})$, e Tween 80 $(1 \mathrm{~mL} / \mathrm{L})$, a pH 5. Foi obtida a suspenção de esporos, do qual $1 \mathrm{~mL}$ foi retirado para contagem em câmara de Neubauer, com auxilio de um microscópio binocular (LEICA), sendo a concentração de esporos fixada em $10^{7} / \mathrm{mL}$. O cultivo ocorreu a $45^{\circ} \mathrm{C}$, durante 96 horas sem agitação. As amostras foram retiradas a cada 24 horas. Para obtenção da massa micelial o meio fermentado foi filtrado a vácuo, em filtro de papel. $\mathrm{O}$ filtro contendo o material fermentado foi seco a $100^{\circ} \mathrm{C}$ até peso constante e a biomassa seca foi utilizada como indicadora do perfil de crescimento.

O filtrado foi centrifugado a $10000 \mathrm{xg}$ por 15 minutos a $5^{\circ} \mathrm{C}$, e o sobrenadante foi utilizado como solução enzimática bruta. Como controle para 
cada fermentação submersa foram preparados frascos erlenmeyers contendo o meio de cultivo sem inóculo. Todas as análises foram realizadas em triplicata.

Acrescidos ao meio básico foram utilizados as fontes de carbono glicose, lactose, xilose e celobiose nas concentrações $0,5 \%$ e $1,5 \%$.

\subsection{Determinação da atividade de endoglucanases (CMCases)}

As atividades de endoglucanase (CMCase) foram determinadas em mistura de reação contendo $100 \mu \mathrm{L}$ do extrato enzimático e $900 \mu \mathrm{L}$ de solução de substrato (CMC Sigma X0502) respectivamente, em solução tampão acetato 0,1 $\mathrm{mol} / \mathrm{L}, \mathrm{pH} 5,0)$. As reações foram mantidas a $60^{\circ} \mathrm{C}$, por 10 minutos e, então, interrompidas pela adição de $1000 \mu \mathrm{L}$ do reagente DNS (ácido1-3dinitrosalicílico) para a quantificação dos açúcares redutores liberados, como proposto por Miller (1959), a partir da curva padrão de glicose. Uma unidade de atividade enzimática foi definida como a quantidade de enzima necessária para liberar $1,0 \mu \mathrm{mol}$ de açúcar redutor por minuto, sob as condições de ensaio citadas.

\section{RESULTADOS E DISCUSSÕES}

Na Figura 1 são apresentados os resultados das concentrações de micélio seco obtido em cultivo líquido em função do tempo em resposta às variações das fontes de carbono na concentração de $0,5 \%$ (a) e $1,5 \%$ (b).

Como pode ser observado, houve uma variação significativa no perfil de crescimento do fungo quando cultivado em diferentes concentrações de fontes de carbono. A máxima concentração de micélio foi obtida em 0,5\% de glicose em 72 horas de crescimento. Na concentração de 1,5\% em glicose, pode ser observado um crescimento acelerado até 24 horas de crescimento e uma tendência quase constante nos tempos subsequentes.

O fungo apresentou uma capacidade restrita de crescimento em lactose, xilose e celobiose a $0,5 \%$. Entretanto, a concentração de biomassa aumentou consideravelmente a $1,5 \%$ de lactose, onde uma tendência do aumento da biomassa, assim como as fases de crescimento podem ser visualizadas. A fase latência parece estar compreendida nas primeiras 24 horas de cultivo, a fase de crescimento acelerado de 24 a 72 horas, a fase estacionária entre 72 e 96 horas, seguida da queda do crescimento a partir de 96 horas. 


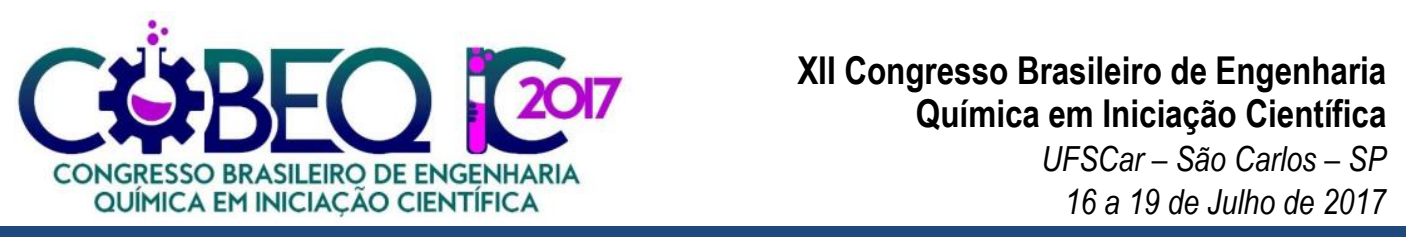

Figura 1 - Cinética de crescimento do fungo Myceliophthora thermophila M.7.7 cultivado nas concentrações de $0,5 \%$ (a) e $1,5 \%$ (b) das fontes de carbono glicose, lactose, xilose e celobiose.
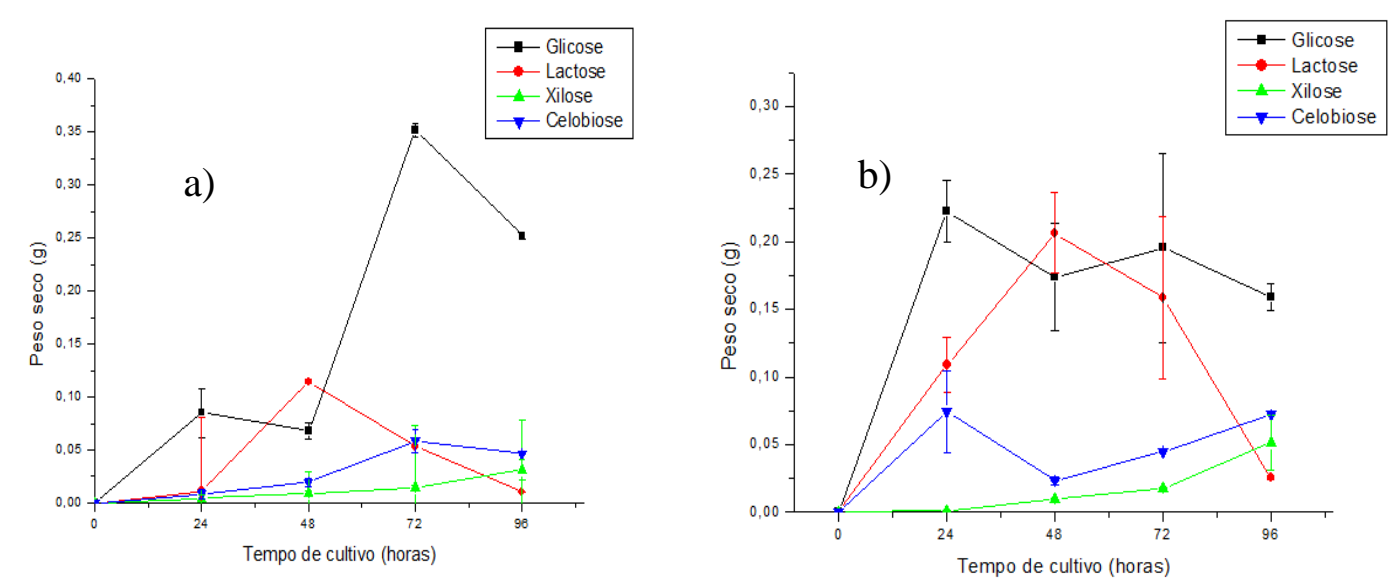

Nos fungos filamentosos a disponibilidade de fontes de carbono mais facilmente metabolizáveis regula a produção de enzimas hidrolíticas. A Figura 2 representa a dinâmica da biossíntese de enzimas celulolíticas em resposta às variações das fontes de carbono na concentração de $0,5 \%$ (a) e 1,5\% (b).

Apesar de o crescimento micelial ter sido inexpressivo quando o fungo foi cultivado em $0,5 \%$ de xilose e celobiose, observa-se uma tendência similar na biossíntese de celulases, mostrando um aumento na atividade enzimática e queda após atingirem o máximo em 72 horas de cultivo. Já na concentração de 1,5\% de xilose houve um pico de atividade em 24 horas de cultivo e nenhuma atividade foi encontrada a partir de 48 horas. Comportamento similar foi observado quando o fungo foi cultivado em glicose a 1,5\%, porém houve eficiência na produção de biomassa. Brienzo et al., (2012) constataram que a xilose pode atuar como molécula indutora em Thermoascus aurantiacus induzindo a produção de xilanase, $\beta$-glicosidase e endoglucanases. Em contrapartida, altos níveis de xilose ou glicose no meio, ativam o chamado sistema de repressão catabólica por carbono em diversos fungos. Este sistema de repressão a nível transcricional impede que haja maciça produção de celulases e hemicelulases de maneira desnecessária para o organismo.

No cultivo em celobiose a 1,5\% a síntese de celulase iniciou-se após 24 horas e atingiu o máximo em 48 horas seguido de um decréscimo na atividade. Muitos celooligossacarídeos e seus derivados têm sido reportados na literatura como potenciais indutores de enzimas celulolíticas. A celobiose, um dissacarídeo de glicoses ligadas por ligação $\beta-1,4$, tem sido observada como um importante indutor de celulases. No trabalho de Mandels et al., (1960) foi investigado a influência da celobiose na indução de celulases pelo fungo Trichoderma viride e 
constataram que a capacidade de indução da celobiose está estreitamente relacionada a sua concentração no meio. Quando o fungo foi crescido em celobiose a uma concentração de $0,5 \%$, a síntese de celulases foi baixa. Já quando os mesmos $0,5 \%$ foram lentamente adicionados ao meio de cultivo durante três dias, houve um aumento expressivo na síntese das enzimas celulolíticas. Os autores concluíram que estes produtos solúveis entram na célula, porém são lentamente consumidos.

A atividade enzimática aumentou consideravelmente na presença de lactose a 1,5\% atingindo o máximo em 48 horas, onde foi possível correlaciona-la diretamente com o crescimento fúngico.

Os resultados deste trabalho estão de acordo com o estudo de Sen et al., (1983) os quais estudaram a biossíntese de enzimas extracelulares do fungo Myceliophthora thermophila D-14 cultivado na presença de glicose, CMC, lactose e celobiose. Os resultados revelaram que a síntese de celulases foi consideravelmente maior na presença de lactose, indicando que o dissacarídeo atua como indutor positivo, já que a lactose possui uma ligação glicosídica similar ao polímero de celulose. Com relação ao crescimento, houve um maior aumento da biomassa na presença de glicose, porém o fungo apresentou capacidade restrita de crescer em celobiose.

Figura 2 - Atividade enzimática de CMCase produzida pelo fungo Myceliophthora thermophila M.7.7 cultivado nas concentrações de $0,5 \%$ (a) e 1,5\% (b) das fontes de carbono glicose, lactose, xilose e celobiose.
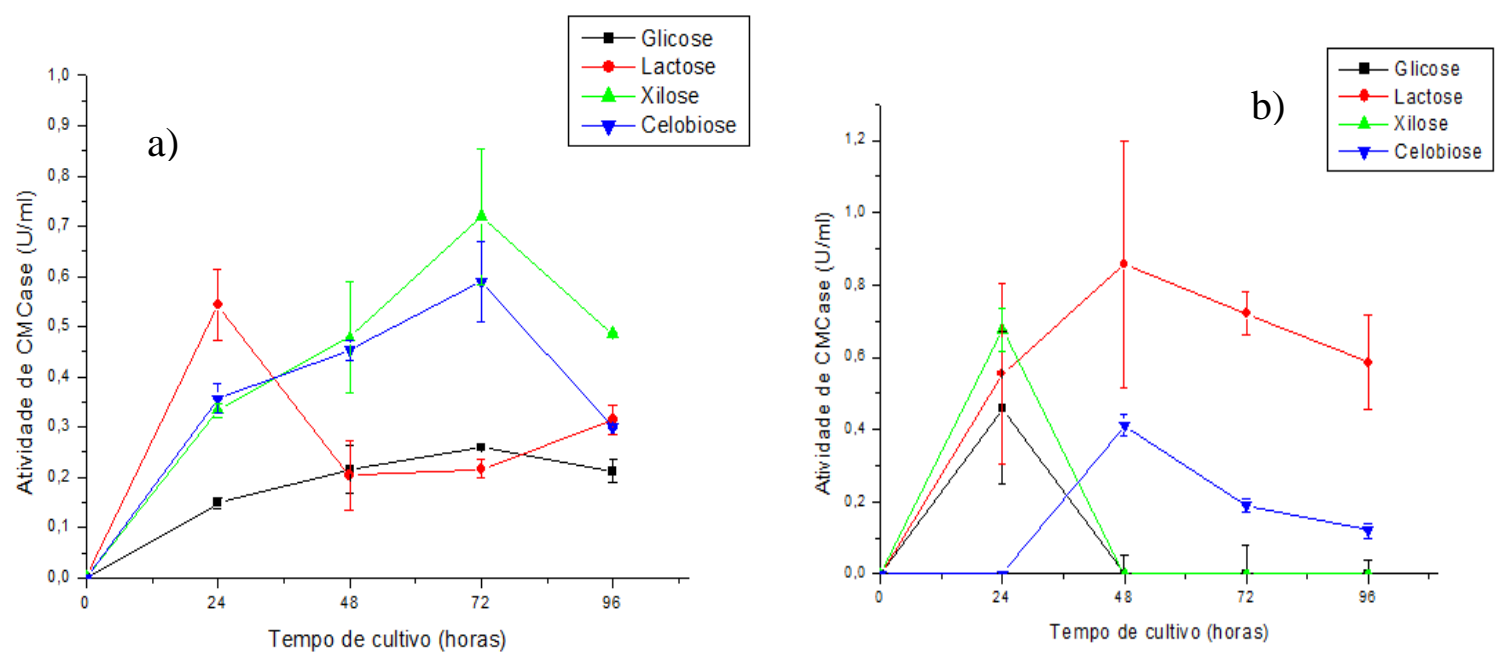

Em contrapartida, Oberson et al., (1992) realizaram uma investigação comparativa em diferentes linhagens do fungo Myceliophthora thermophila não sendo observados crescimento, nem eficiência na produção de enzimas celulolíticas quando a lactose foi usada como fonte de carbono e todas as linhagens apresentaram um bom crescimento em celobiose e glicose.

\section{CONCLUSÕES}


Os resultados apresentados neste trabalho apontam que a concentração de biomassa micelial e a síntese enzimática estão estreitamente relacionadas com o tipo de fonte de carbono utilizada, assim como sua concentração no meio. Altas concentrações de monossacarídeos facilmente assimiláveis no meio podem ser eficientes na produção de biomassa, porém podem causar repressão catabólica por carbono.

\section{REFERÊNCIAS}

BRIENZO, M., MONTE, J. R., MILAGRES, A. M. F. Induction of cellulase and hemicellulase activities of Thermoascus aurantiacus by xylan hydrolyzed products. Microbiol Biotechnol., v.28, p.113-119, 2012.

BERKA R.M, GRIGORIEV I.V, OTILLAR .R, SALAMOV .A, GRIMWOOD .J, REID .I, ISHMAEL. N, JOHN. T, DARMOND. C, MOISAN. MC, HENRISSAT. B, COUTINHO .P.M, LOMBARD. V, NATVIG. D.O, LINDQUIST. E, SCHMUTZ. J, LUCAS. S, HARRIS. P, POWLOWSKI. J, BELLEMARE. A, TAYLOR. D, BUTLER. G, DE VRIES. R.P, ALLIJN. I.E, VAN DEN BRINK. J, USHINSKY. S, STORMS. R, POWELL. A. J, PAULSEN I.T, ELBOURNE L.D, BAKER S.E, MAGNUSON J, LABOISSIERE. S, CLUTTERBUCK A. J, MARTINEZ. D, WOGULIS. M, DE LEON A.L, REY M.W, TSANG A. Comparative genomic analysis of the thermophilic biomassdegrading fungi Myceliophthora thermophila and Thielavia terrestris., Nat. Biotechnol., v. 29, p. 922, 2011.

KRISHNA, C. Solid-state fermentation systems - An Overview. Crit Rev Biotechnol, v.25, p.1-30, 2005.

MANDELS, M., REESE, T. E. Induction of cellulase in fungi by cellobiose. $J$. Bacteriol., v. 79(6), p. 816-826, 1960.

MILLER, G.L. Use of dinitrosalicylic acid reagent for determination of reducing sugar. Analitical Chemistry, v. 31, p.426 - 428, 1959.

MORETTI, M. M. de S. Isolamento de fungos termofílicos produtores de celulases, xilanases e ferruloil esterase para bioconversão de bagaço de cana de açúcar em açúcares fermentescíveis. Dissertação (Mestrado), Universidade Estadual Paulista, Rio Claro, 2010.

OBERSON, J., T. BINZ, D. FRACHEBOUD, AND G. CANEVASCINI. Comparative investigation of cellulose-degrading enzyme systems produced by different strains of Myceliophthora thermophila (Apinis) v. Oorschot. Enzyme Microb Technol., v. 14, p. 300-312, 1992.

SEN, S., T. K. ABRAHAM, and S. L. CHAKRABARTY. Induction of cellulase in Myceliophthora thermophila D-14. Can. J. Microbiol., v. 29, p.1258-1260, 1983. 